\title{
Effects of Different Solvent Polarity on the Quality Characteristics of Conophor Nut Oil
}

\author{
Waliu Adewale Adebayo", Kehinde Adekunbi Taiwo, Olumide Joseph Olubiyo \\ Department of Food Science and Technology, Faculty of Technology, Obafemi Awolowo University, Ile Ife, Nigeria.
}

\begin{abstract}
How to cite this paper: Waliu Adewale Adebayo, Kehinde Adekunbi Taiwo, Olumide Joseph Olubiyo. (2021) Effects of Different Solvent Polarity on the Quality Characteristics of Conophor Nut Oil. International Journal of Food Science and Agriculture, 5(2), 339-345. DOI: 10.26855/ijfsa.2021.06.020
\end{abstract}

Received: April 29, 2021

Accepted: May 25, 2021

Published: June 29, 2021

*Corresponding author: Waliu Adewale Adebayo, Department of Food Science and Technology, Faculty of Technology, Obafemi Awolowo University, Ile Ife, Nigeria.

Email: adebayoadewale@ymail.com

\begin{abstract}
This study investigated the effect of different extraction solvents on physico-chemical and fatty acid compositions of conophor nut oil (Tetracarpidiumconophorum). Solvent extraction was done using Soxhlet and physico-chemical properties and fatty acid profiles of the oils were carried out using standard procedure. The oil yields of conophor nut oil ranged from $43.77 \%$ (ethanol) to $46.72 \%$ (n-hexane). The physico-chemical properties values such as iodine number; refractive index; saponification value; acid value; peroxide value; viscosity at $25^{\circ} \mathrm{C}$ and colour were $23.46-28.31 \mathrm{~g} \mathrm{I}_{2} / 100 \mathrm{~g} ; 1.52-1.66 ; 190.90-199.16 \mathrm{mg}$ $\mathrm{KOH} / \mathrm{g}$; 2.41-2.62 mg NaOH/g; 3.47 to 4.28 meq $\mathrm{O}_{2} / \mathrm{g}$; $11.43-13.98 \mathrm{mPa}$.; light yellow to deep yellow, respectively. The fatty acid compositions of the oil showed that saturated and unsaturated components ranged from $5.18-7.81 \%$ and 83.1-93.13\%, respectively. Some of the saturated components of conophor nut oil include palmitic; cerotic; melissic; valeric and tridecyclic while its unsaturated components are oleic; isooleic; petroselinic; linolenic; alpha-linolenic and eicosatrienoic. In conclusion, the results showed that different solvents used in extraction of the conophor nut oil affected some physico-chemical properties of the oil. Similarly, fatty acid compositions were also affected. The properties investigated showed that the oil can find its usage food formulation and chemical industries.
\end{abstract}

\section{Keywords}

Conophor Nut, Oil, Solvents, Extraction Methods, Quality Characteristics

\section{Introduction}

Oil bearing seeds, some of which include cotton, castor, sunflower, groundnut, cashew, pistachio and shea nut have greatly contributed to the economic development of many countries in the world [1]. Most oilseeds are typically high in fat $(45-70 \%, w / w)$ and protein $(20-25 \% \mathrm{w} / \mathrm{w})$ and are therefore energy-rich foods [2]. Vegetable oils obtained from oilseeds have been widely explored in the world market as major commodities [3]. Oilseeds and their products have been playing an important role in our day to day lives since ages and they serve as source of macro and micro nutrients to human and animal for growth and health management [4]. Some of the well-known edible nuts are almond, cashew, pistachio and walnut; however there are several others which are not popular and have not been fully explored for food and industrial purposes. Conventional oilseeds have been widely explored in different food formulations as source of vegetable proteins and oils [5]. But, the ever-increasing demand for vegetable oil from conventional oilseeds has necessitated needs for alternative source of oil from cheaper, unconventional oilseeds.

Conophornut (Tetracarpidium conophorum) is an underutilized oilseed often grown as a climber in the forest regions of Africa and India [6]. In Nigeria, it is predominantly found in the Southwest States such as Oyo, Osun, Ekiti, Ogun and Ondo. It is known as Ekporo by Efik and Ibibios of Cross River and Akwa Ibom, as Ukpa in Ibo, Awusa or Asala in Yoruba, Okwe in Edo and Gwandi bairi in Hausa [7]. Therefore, the need for economical yet abundant sources of oils to fill in the gap between demand and supply of vegetable oil is a reason for this study. This study will explore the possibility of increasing the utilization of conophor oil and for both domestic and industrial applications through scientific 
investigations of quality parameters affected by various extraction techniques.

\section{Materials and Methods}

Source of Materials: Mature conophor nut was obtained from Teaching and Research Farm of Obafemi Awolowo University, Ile-Ife, Nigeria.

Sample Preparation: The nuts was sorted, washed with potable water to remove attached dirt, cleaned to remove foreign materials, packaged in polythene bags and stored in refrigerated condition till time of use. The cleaned nuts were cooked, decorticated, dried, fine milled and then divided into three portions: the first portion was extracted using ethanol; the second portion was extracted using acetone while the third portion was extracted using hexane. Analytical grade solvent was used. The extraction was done in triplicates. The oil was recovered by complete evaporation of the solvent on a heating mantle, the recovered oil was transferred to a beaker and the beaker was placed over water bath for complete evaporation of the solvent for about $2 \mathrm{~h}$. The flow chart for the solvent extraction is presented in Figure 1.

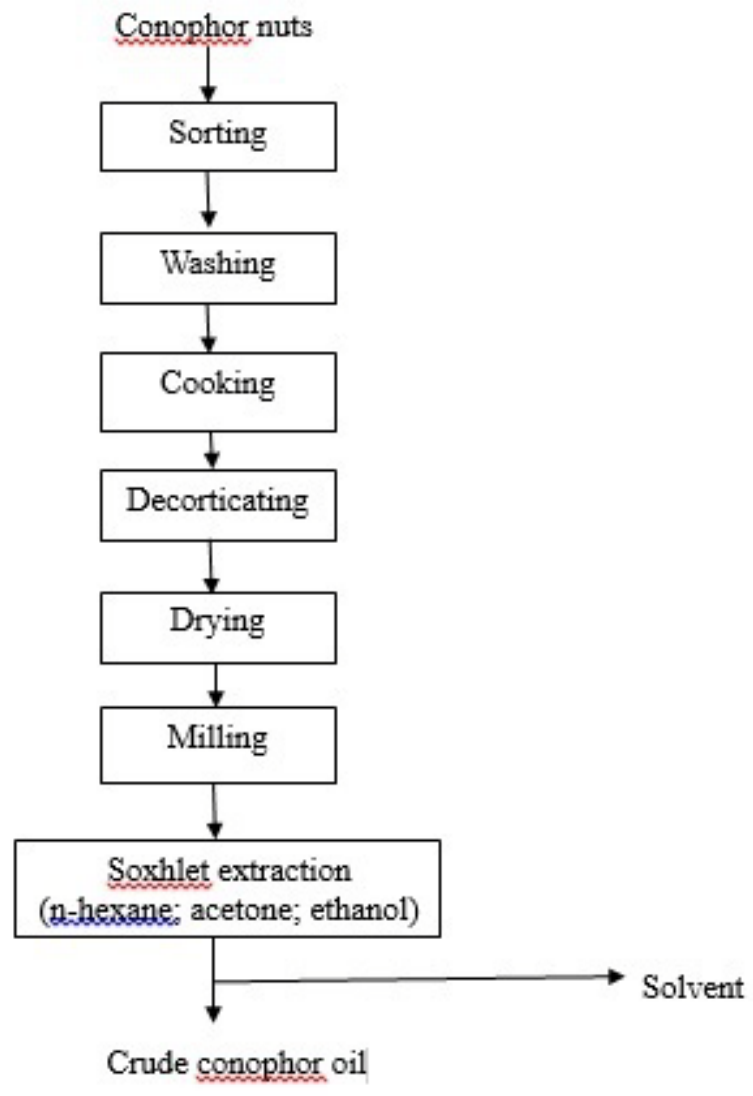

Figure 1. A flow chart showing extraction of crude conophor oil.

weighing balance (Model Mettler PE1600, Mettler Instruments Corporation, Greifensee, Zurich, Switzerland) with an accuracy of $0.1 \mathrm{mg}$.

\subsection{Oil yield determination}

Oil yield was determined using method documented by [1]. Mass of the recovered oil from known mass of ground conophor nut was measured using weighing balance (Model Mettler PE1600, Mettler Instruments Corporation, Greifensee, Zurich, Switzerland) with an accuracy of $0.1 \mathrm{mg}$. The oil yield was calculated using equation (1):

$$
O Y \%=\frac{M o}{M s} \times 100
$$

Where;

$M S$ = Mass of ground conophor nut (g); $O Y=$ Oil yield (\%); $M o=$ Mass of extracted conophor oil (g)

\subsection{Determination of saponification number}

About $2.00 \mathrm{~g}$ of oil was introduced into a $250 \mathrm{ml}$ Erlenmeyer flask and exactly $25 \mathrm{ml} 0.5 \mathrm{~N}$ alcoholic $\mathrm{KOH}$ solutions 
was added. This was refluxed in boiling water bath for $1 \mathrm{hr}$ and then shaken frequently; $1.00 \mathrm{ml}$ of phenolphthalein (1\%) solution was added and titrated hot with the excess alkali with $0.5 \mathrm{~N} \mathrm{HCl}$ (titration $=\mathrm{a}$ ml). A blank would be carried out at the same time (titration $=\mathrm{b} \mathrm{ml}$ ) [8].

$1 \mathrm{ml} 0.5 \mathrm{~N} \mathrm{HCl}=0.02805 \mathrm{~g} \mathrm{KOH}$ hence

$$
S V=\frac{(b-a)}{W s} \times 28.05 \mathrm{mgKOH} / \text { goil }
$$

Where: $\mathrm{SV}=$ saponification value; $\mathrm{Ws}=$ Weight of sample in grams

\subsection{Acid value determination}

About $1.00 \mathrm{~g}$ of the oil sample was dissolved in $50 \mathrm{ml}$ of the neutral solvent in $250 \mathrm{ml}$ conical flask. About 3-4 drops of the phenolphthalein indicator was added to the sample in the conical flask. The content was titrated against $0.10 \mathrm{M}$ $\mathrm{KOH}$ and then shaken constantly until a pink colour which persisted for $15 \mathrm{~s}$ would have disappeared. Blank titration will also be done under the same condition. The acid value will then be calculated using equation (3).

$$
A V=\frac{V}{W s} \times 100 \%
$$

Where:

AV = Acid value (g/oil); Ws = Weight of sample used (g): V = Titre value (ml)

\subsection{Iodine value determination}

About $0.25 \mathrm{~g}$ of sample was weighed into $500 \mathrm{ml}$ flask or bottle and dissolved with $10 \mathrm{ml}$ chloroform $\left(\mathrm{CHCl}_{3}\right) .25 \mathrm{ml}$ Hanus iodine solution was added and a left in a dark cupboard for 30mins. It was shook occasionally. $10 \mathrm{ml} 15 \% \mathrm{KI}$ solution was added and shook thoroughly. $100 \mathrm{ml}$ freshly boiled and cooled water was added to wash down free iodine on stopper. Few drops of starch indicator were added. Titration with $0.1 \mathrm{~N} \mathrm{Na}_{2} \mathrm{~S}_{2} \mathrm{O}_{3}$ was done gradually till blue colour entirely disappears. Experiment was done in duplicate and blank titration was carried out alongside.

$$
I V=\frac{(b-a) \times N \times 12.691}{W}
$$

Where:

IV = Iodine value (g/100g); $\mathrm{b}=$ Titration of blank sample (ml); $\mathrm{a}=$ Titration of oil sample (ml); $\mathrm{W}$ = weight of sample (g).

\subsection{Peroxide value determination}

Peroxide value was determined according to a method described by [2]. This method is based on the ability of lipid peroxide to oxidise the $\mathrm{Fe}^{2+}$ to $\mathrm{Fe}^{3+}$ by hydroperoxides and formation of the reddish $\mathrm{Fe}$ (III)-thiocyanate complex for spectrophotometric determination of peroxide value. $0.06 \mathrm{~g}$ of sample was dissolved with $1 \mathrm{~mL}$ chloroform/acetic acid (2:3) in a screw cap test tube. The mixture was shook intermittently for 30 min. $0.10 \mathrm{ml} \mathrm{Fe}{ }^{2+}$ solution and $\mathrm{NH}_{4} \mathrm{SCN}$ $(0.44 \mathrm{~N})$ were added to the mixture. Mixture was incubated and left in the dark for 10mins. Sample mixture was done in triplicate. Blank mixture was done alongside. Blank was carried out by mixing all reagents without mixing oil. Absorbance was measured using a spectrophotometer at a wavelength of $510 \mathrm{~nm}$. Slope was determined from the graph of absorbance against $\mathrm{Fe}^{3+}$ concentration.

$$
\begin{aligned}
P V I_{I D F} & =\frac{A_{s}-A_{b}}{55.84 \times 2 \times m \times W_{s}} \\
P V I_{I D F} & =1.027 \times P V_{A O A C}-3.568
\end{aligned}
$$

Where: $\mathrm{PV}$ IDF $=$ peroxide value; $\mathrm{A}_{\mathrm{s}}=$ absorbance of sample; $\mathrm{A}_{\mathrm{b}}=$ absorbance of blank; $\mathrm{m}=$ slope; Ws = Weight of sample used (g)

\subsection{Refractive index determination}

The refractive indices of the oil samples was determined by placing two drops of the oil samples on the prism of Abbe refractrometer model, (serial number AX00474 by Bellingham Stanley Limited, 2014) by means of a syringe and the prism was firmly closed by tightening the screw head. The instrument will then be allowed to stand for 15 minutes before taking down the reading displayed on the screen.

\subsection{Viscosity determination}

Viscosity of the oil was determined by using a U-tube Viscometer also known as glass capillary viscometer with a selection of a spindle which was properly fixed to the holder. Liquid was drawn into the upper bulb by suction (using a 
pipette filler), then allowed to flow down through the capillary into the lower bulb. Two marks (one above and one below the upper bulb) indicated a known volume. The time taken for the level of the liquid to pass between these marks was recorded. Viscosity was gotten by multiplying the time taken by the factor of the viscometer and density of the oil. The viscosity value of the oil was measured in $\mathrm{mPa}$ s. Colour of the oil was determined by physical observation of the oil sample.

\subsection{Fatty acid determination}

Fatty acid profile was determined using gas chromatography analysis performed on Agilent equipment with single quadrupole mass spectrometer detector and split/splitless injector. Fatty acids (FAs) were determined using indirect method, where they were converted to corresponding methyl esters (FAMEs) during trimethylsulfonium hydroxide solution reaction. Quantification of individual fatty acids was based on two different methods. Firstly, it was based on the received peak area, and the results were normalized without correction factor. Secondly, the quantification was based on external calibration curve, for 34 identified fatty acids [9].

\section{Statistical Analysis}

Data obtained was analysed descriptively and inferentially using analysis of variance (ANOVA), and Tukey test.

\section{Results and Discussion}

The oil yield values of conophor nut oil ranged from $43.8 \%$ to $46.76 \%$ (Table 1 ). There is a significant difference (p $<0.05$ ) in the conophor oil yield. The values showed that extraction using polar solvents (acetone and ethanol) have lower oil yield compared to non-polar solvent (n-hexane). This showed that dielectric constant (a measure of solvent polarity) is a key parameter in determining the solvent interactions [10]. The dielectric constants of n-hexane, acetone and ethanol are 2.01; 20.7 and 24.3, respectively. These values showed that increase in dielectric constant leads to corresponding decrease in percentage oil yield. The highest oil yield was obtained from non-polar (n-hexane) which has a dielectric constant ranging from 1.9-2.01 while the least oil yield was obtained from ethanol with dielectric constant of 24.3. Similar trend was reported for sesame seed oil [11].

The refractive indices values are 1.52, 1.66 and 1.64 for ACESO, HEXSO and ETHSO, respectively. The result showed that refractive index ranged from 1.52 to 1.66 but there is no significant difference $(\mathrm{p}<0.05)$. The results obtained are higher than 1.47 documented for groundnut and cashew oils but compared favourably with 1.66 documented for cassia oil [12].

Table 1. Physio-chemical properties of conophor nut oil

\begin{tabular}{cccc}
\hline Properties & HEXSO & ACESO & ETHSO \\
\hline Oil yield (\%) & $46.72 \pm 0.63^{\mathrm{c}}$ & $45.44 \pm 0.13^{\mathrm{b}}$ & $43.77 \pm 0.43^{\mathrm{a}}$ \\
Iodine number (g I $/ 100 \mathrm{~g})$ & $27.29 \pm 0.03^{\mathrm{b}}$ & $23.46 \pm 0.04^{\mathrm{c}}$ & $28.31 \pm 0.01^{\mathrm{a}}$ \\
Refractive index & $1.66 \pm 0.00^{\mathrm{a}}$ & $1.52 \pm 0.01^{\mathrm{b}}$ & $1.64 \pm 0.01^{\mathrm{a}}$ \\
Saponification value (mg KOH/g) & $190.90 \pm 0.00^{\mathrm{b}}$ & $199.16 \pm 0.00^{\mathrm{c}}$ & $195.05 \pm 0.14^{\mathrm{a}}$ \\
Acid value (mg NaOH/g) & $2.48 \pm 0.01^{\mathrm{c}}$ & $2.62 \pm 0.01^{\mathrm{a}}$ & $2.41 \pm 0.01^{\mathrm{b}}$ \\
Peroxide value (meq $\left.\mathrm{O}_{2} / \mathrm{g}\right)$ & $3.47 \pm 0.035^{\mathrm{b}}$ & $3.53 \pm 0.04^{\mathrm{b}}$ & $4.28 \pm 0.01^{\mathrm{a}}$ \\
Viscosity (mPa.s) at $25^{\circ} \mathrm{C}$ & $13.27 \pm 0.00^{\mathrm{b}}$ & $11.43 \pm 0.01^{\mathrm{c}}$ & $13.98 \pm 0.01^{\mathrm{a}}$ \\
Physical observation (Colour) & Golden yellow & Yellow & Deep yellow \\
\hline
\end{tabular}

Values on the same row followed by different superscripts differ significantly at $\mathrm{p}<0.05$ mean \pm standard deviation values reported.

Refractive index is an important property which helps in the detection of adulteration in vegetable oils, as it is related to their molecular weight, fatty acid chain length and degree of unsaturation [3].

The result of the viscosity is shown in the Table 1 . The result shows a decrease in viscosity with increase in temperature, which is an attribute of Newtonian fluid. It showed ETHSO had maximum viscosity (13.98 mPa.s) and ACESO had minimum viscosity $(11.43 \mathrm{mPa} . \mathrm{s})$. The significant difference $(\mathrm{p}<0.05)$ in viscosity at all temperature is observed to be due to amount of saturation. Oil viscosity decreases slightly with increase in saturation. It is thus a quality parameter. It is necessary for design of; piping, tank, and process equipment for oil bearing materials [3]. ACESO had the lowest composition of saturated fatty acids (5.18\%) while ETHSO and HEXSO had higher compositions; 6.24\% and 7.81\%, respectively. However, ETHSO had maximum composition of unsaturated fatty acid while ACESO showed the minimum; $93.13 \%$ and $83.10 \%$ respectively. The result showed similar trends reported for corn oil, rapeseed oil soybean oil and olive oil [13] for different vegetable oils.

Colour from physical observation of ETHSO, HEXSO and ACESO were; deep yellow, golden yellow and yellow, 
respectively. The color is used as an indication of adulteration of oils [14]. Similar trend of colour, from physical observation, of groundnut, canola and soybean oils were reported by [3]. The colour of seeds is also usually affected by seed varieties, maturity and environment [15].

The result of iodine values obtained ranged from 23.43-28.31g $\mathrm{I}_{2} / 100 \mathrm{~g}$. Iodine value is used to determine the amount of unsaturation contained in form of fatty acids as its value is directly proportional to degree of unsaturation. The higher the unsaturation, the more unsaturated fatty acids present in a fat which determines the stability of oils to oxidation [16].

The result showed that ACESO had least iodine value $\left(23.46 \mathrm{~g} \mathrm{I}_{2} / 100 \mathrm{~g}\right)$, thus the least degree of unsaturation, while ETHSO had the highest iodine value $\left(28.31 \mathrm{~g} \mathrm{I}_{2} / 100 \mathrm{~g}\right)$ therefore has the highest degree of unsaturation. Oils with values less than 100 are classified as non-drying oils (such as coconut and olive oils), which have a variety of industrial uses. One of the uses of non-drying oils is in the preparation of soaps, cleansers, lubricants, candles, cosmetics etc. Its use for this is cause of its fewer tendencies to deteriorate to any appreciable extent due to oxidation and polymerization [3].

The peroxide values ranged from $3.53-4.28 \mathrm{meq} \mathrm{O}_{2} / \mathrm{g}$. The result showed no significant difference $(\mathrm{p}<0.005)$ with HEXSO having the minimum value (3.53meq $\mathrm{O}_{2} / \mathrm{g}$ ) while ETHSO having the maximum value $\left(4.28 \mathrm{meq} \mathrm{O}_{2} / \mathrm{g}\right.$ ). Peroxide value is standard used to measure the rancidity of oils and estimate the keeping qualities of oils. The values obtained are within the maximum acceptable range for edible oils which is 1-10 meq $\mathrm{O}_{2} / \mathrm{g}$ documented by [17].This shows that the oils are stable to relative oxidation and can be stored for a long period of time with minimum deterioration and rancidity. Peroxide value measures closely rancidity of lipids during the initial stages of lipid oxidation because the value increases to a maximum and then decreases as storage time increases [17].

The result of the saponification values ranged from 190.9-199.16 mg KOH/g and showed significant difference $(\mathrm{p}<0.005)$ with HEXSO having the minimum value and ACESO having maximum value. Saponification number is a measure of the average molecular weights of all the fatty acids present in the oil. It measures the length of the fatty acid chain in the oil as well as indicating the nature of fatty acid chains esterified by glycerol [2]. The results followed similar trends of pumpkin seed oils reported by [18].

The result of acid values were 2.48; 2.62 and $2.41 \mathrm{mg} \mathrm{KOH/g}$ for HEXSO, ACESO and ETHSO, respectively and showed significance difference $(\mathrm{p}<0.05)$. Acid value is the measure of the number of carboxylic acid groups (FFA) present. The acid value of oils can be used to determine the quality of the oil, high acid value more oxdisable it is [2]. The values obtained was higher than the $1.1 \mathrm{mg} \mathrm{KOH} / \mathrm{g}$ acid value of soybean oil but compared favourably to the 2.2-2.6mg KOH/g acid value from peanut oil [19]. Acid value is also a quality parameter of biodiesel. Acid value must be $<0.50 \mathrm{mg} \mathrm{KOH} / \mathrm{g}$ in both EN 14214 and ASTM D6751 standards for it to be acceptable in biodiesel production. This is because the acid may corrode automotive parts and these limits protect vehicle engines and fuel tanks. Therefore, conophor nut oil may not suitable for biodiesel production.

Effect of extraction solvents on fatty acid compositions of conophor nut oil is presented in Table 2. The ratio of polyunsaturated fatty acid to saturated fatty acid (P/S index) for HEXSO, ACESO and ETHSO samples were 9.23; 13.42 and 12.41, respectively. The P/S index is an important parameter for determination of nutritional value in vegetable oil. Oils and fats with P/S index values higher than 1 are considered having higher nutritional values. Lawton et al. (2000) [20] reported that a higher P/S value means smaller deposition of lipids in the body. The P/S index values of conophor nut oils are higher than $0.005 ; 1.91 ; 4.26$ and 7.05 for coconut oil, corn oil, soybean oil and linseed oil, respectively but compared favourably with 10.55 reported for safflower oil [21]. The palmitic acid (C16:0) composition of the oil ranged from 2.49-2.72\% with sample ETHSO having the maximum composition. The palmitic acid values obtained were lower than $12.9 \%$ reported for sesame oil [2]. Although palmitic acid can significantly raise low-density lipoprotein (LDL) cholesterol levels more than other SFAs, it is beneficial to the skin and serves as a source of energy [4]. Cerotic acid (C26:0), a very long chain SFA, values for samples HEXSO and ETHSO ranged between $3.42-3.52 \%$ whereas it was determined in sample ACESO.

Melissic acid (C30:0), another very long chain SFA found commonly in beeswax, was the predominant in ACESO with composition value of $2.69 \%$. The melissic acid composition obtained compared favourably with $0.11 \%-3.57 \%$ in cassia stem and leaves reported by [14]. Due to the evidence that SFAs have different effects on the concentration of plasma lipoprotein cholesterol fractions, it is recommended that SFA should be replaced with PUFA ( $n-3$ and n-6) in diet and the total intake of SFA not exceed 10\% [22]. The Table 2 further showed that only sample HEXSO contained Valeric acid (C5:0). Valeric acid (C5:0) is a short straight-chain SFA plant metabolite responsible for the fruity odour of plant. Another short chain SFA, Tridecyclic acid (C13:0), was only present in HEXSO in 1.76\%.Tridecyclic acid is a metabolite produced during metabolic reaction in plants kingdom that includes flowering plants, conifers and gymnosperms [23].

The result showed omega-3, omega-6 and omega-9 unsaturated fatty acid present in all oils with omega-3, alpha-linoleic (C18:3) acid having a predominant composition in all oil samples. The values of this polyunsaturated fatty acid (PUFA) composition ranged from 58.50\% (ACESO) to 64.89\% (ETHSO). Alpha-linoleic acid (ALA), acts has anti-inflammatory for blood vessels, preventing and treating diseases of the heart. It is used to prevent heart attacks, lower high blood pressure, lower cholesterol, and reverse hardening of blood vessels (atherosclerosis) [24]. The value of 
alpha-linoleic acid was higher than 8.0\%; 11.9\%; $44.0 \%$ and $47.5 \%$ for soybean, canola oil variety 1, canola variety 2 and linseed oil, respectively [21]. Omega-6 PUFA, linoleic acid (C18:2), was extracted by all solvents with values of composition ranging from $11.03 \%$ (ACESO) to $12.58 \%$ (ETHSO). Linoleic acid is associated with lower mortality rate and attributed lower incidence of cardiovascular diseases [23].

Table 2. Effect of extraction solvents on fatty acid compositions of conophor nut oil

\begin{tabular}{|c|c|c|c|}
\hline \multicolumn{4}{|c|}{ Saturated fatty acids } \\
\hline Sample/Fatty acid & HEXSO (\%) & ACESO (\%) & ETHSO (\%) \\
\hline Palmitic acid (C16:0) & 2.50 & 2.49 & 2.72 \\
\hline Cerotic acid (C26:0) & 3.42 & ND & 3.52 \\
\hline Melissic acid (C30:0) & ND & 2.69 & ND \\
\hline Valeric acid (C5:0) & 0.16 & ND & ND \\
\hline Tridecyclic acid (C13:0) & 1.73 & ND & ND \\
\hline Total saturated fatty acids & $7.81 \pm 0.01^{\mathrm{a}}$ & $5.18 \pm 0.01^{b}$ & $6.24 \pm 0.00^{\mathrm{c}}$ \\
\hline \multicolumn{4}{|c|}{ Unsaturated fatty acids } \\
\hline Oleic acids (C18:1) (monounsaturated) & 16.73 & 13.57 & ND \\
\hline Isooleic acid (C18:1) (monounsaturated) & 0.40 & ND & 15.17 \\
\hline Petroselinic acid (C18:1) (monounsaturated) & ND & ND & 0.49 \\
\hline Linoleic acid (C18:2) (polyunsaturated) & 11.58 & 11.03 & 12.58 \\
\hline Alpha-linoleic acid (C18:3) (polyunsaturated) & 60.30 & 58.50 & 64.89 \\
\hline Eicosatrienoic acid (C20:3) (polyunsaturated) & 0.21 & ND & ND \\
\hline Total monounsaturated fatty acid & 17.13 & 13.57 & 15.66 \\
\hline Total polyunsaturated fatty acid & 72.09 & 69.53 & 77.47 \\
\hline Polyunsaturated/Saturated (P/S) index & 9.23 & 13.42 & 12.41 \\
\hline Total unsaturated fatty acid & $89.22 \pm 0.01^{\mathrm{b}}$ & $83.1 \pm 0.00^{c}$ & $93.13 \pm 0.01^{\mathrm{a}}$ \\
\hline
\end{tabular}

Values on the same row followed by different superscripts differ significantly at $\mathrm{p}<0.05$ mean \pm standard deviation values reported. ND means Not Determined.

The composition values of linoleic acid compared favourable to 15.2\%-18.8\% for canola oil [21]. Oleic acid (C18:1) was the predominant monounsaturated fatty acid (MUFA) present in ACESO and HEXSO samples. An isomer of oleic acid, iso-oleic acid (C18:1), was found to be the dominant MUFA in ETHSO (15.17\%) and minute composition found in HEXSO (0.40\%) denoting high isomerization reaction occurring in oil extracted by ethanol. Iso-oleic acid is a mixture of C18-unsaturated branched chain fatty acid isomers with a methyl group on various positions of the alkyl chain, which is the product of skeletal isomerization reaction of oleic acid [2]. Another isomer of oleic acid, petroselinic acid (C18:1), with composition $0.49 \%$ was in ETHSO. Oleic acid and its isomers helps in reduction of inflammation, modulation of leukocytes activity, enhancements of bactericidal and fungicidal action, inhibition of cancer proliferation and oncogenes expression, reduction of blood pressure and attenuation of effects of autoimmune diseases [24]. The value of oleic acid and its isomers was lower than 24.9\%; $28.0 \%$; $41.5 \%$ and $42.7 \%$ for pumpkin seed, safflower, sesame seed and rice bran oils respectively but compared favourably to 6.2; 11.5 and 12.7 for coconut, safflower and wheat germ oils, respectively [25]. The samples showed significant differences $(\mathrm{p}<0.05)$ in total unsaturated fatty acid with values ranging from $83.1 \%$ (acetone) to $93.1 \%$ (ethanol).

\section{Conclusion}

This study showed that solvent polarity affected physico-chemical properties with the exception of refractive index, peroxide value and colour of the oil samples. Different extraction solvents affected fatty acid compositions of the oils. The physico-chemical properties of conophor nut oil showed that the oil can find its application in food formulation and chemical industries subject to further clarification.

\section{Acknowledgements}

Dr. Waliu Adewale Adebayo acknowledges Dr. S. O. Gbadamosi for being the one who inspired interest to work on conophor (Tetracarpidium conophorum) nut. 


\section{References}

[1] Bamgboye, I. B. and Adejumo, O. I. (2010). Physicochemical properties of roselle seed oil. Nutrition and Food Science, 40, 185-192.

[2] Gbadamosi, S. O., Fasuan, T. O., and Omobuwajo, T. O. (2017). Fatty acid profile, physio-chemical and functional properties of oil and protein isolate simultaneously extracted from sesame (Sesamum indicum) seed. Annals Food Science and Technology, 18(1), 1-10.

[3] Adebayo, W. A., Ogunsina, B. S., and Gbadamosi, S.O. (2015). The effect of cold pressing and solvent extraction on some characteristics of kariya (Hildergadia barteri) seed oil. Nutrition and Food Science, 45(4), 625-633.

[4] Carta, G., Murru, E., Banni, S., and Manca, C. (2017). Palmitic Acid: Physiological Role, Metabolism and Nutritional Implications. Frontiers in Physiology, 8, 902-913.

[5] Alobo, A. P., Agbo, B. N., and Ilesanmi, S. A. (2009). Physicochemical and functional properties of full fat and defatted cashew kernel flours. International Journal of Food Science and Technology, 44, 581-585.

[6] Edem, C. A., Dosunmu, I. M., and Bassey, F. I. (2009). Determination of proximate composition, ascorbic acid and heavy metal content of African walnut (Tetracarpidium conophorum). Pakistan Journal of Nutrition, 8, 225-226.

[7] Nwaoguikpe, R. N., Ujowundu, C. O., and Wesley, B. (2012). Phytochemical and biochemical compositions of African walnut (Tetracarpidium conophorum). Journal of Pharmaceutical and Biomedical Sciences, 20(9), 1-5.

[8] AOAC. (2002). Official Methods of Analysis. Association of Analytical Chemists Gaithersburg Maryland, USA.

[9] CODEX STAN 210. (1999). Codex Standard for Named Vegetable Oils. www.codexalimentarius.org/input/download/stand ards/[...]/CXS_210e.pdf. Accessed28thDecember, 2015.

[10] Nwabueze, T. U. and Okocha, K. S. (2008). Extraction performances of polar and non-polar solvents on the physical and chemical indices of African breadfruit (Treculia africana) seed oil. African Journal of Food Science, 2(10), 119-125.

[11] Tir, R., Dutta, C. P., and Badjah-Hadj-Ahmed, Y. A. (2012). Effect of the extraction solvent polarity on sesame seeds oil composition. European Journal of Lipid Science and Technology, 114, 1427-1438.

[12] Gungstone, F. D. (2002). Vegetable oil in food technology: Composition, properties and uses, Blackwell Publishing, Oxford, 7-17.

[13] Rukke, E. and Schuller, B. F. (2017). Viscosity of a selection of edible oils and blends of oils at different temperatures. Annual Transactions of the Nordic Rheology Society, 25: 287-292.

[14] Shukla, A. K., Dixit, A. K., and Singh, R. P. (2005). Detection of adulteration in edible oils. Journal of Oleo Science, 54(6), 317-324.

[15] Alfatni, M., Shafri, H., and Shariff, R. (2008). Oil palm fruit bunch grading system using red, green and blue digital number. Journal of Applied Sciences, 8(8), 1444-1452.

[16] Asuquo, J. E., Ukpong, I. U., Etim, E. E., and Etuk, S. E. (2012). Extraction, characterization and fatty acid profile of Poga oleosa oil. International Journal of Modern Analytical and Separation Sciences, 1(1), 23-30.

[17] Akinoso, R., Aboaba, S. A., and Olayanju, T. M. A. (2010). Effects of moisture content and heat treatment on peroxide value and oxidative stability of un-refined sesame oil. African Journal of Food, Agricuture, Nutrition Development, 10(10), 4268-4285.

[18] Chatepa, L. E. C. and Masamba, K. (2019). The influence of solvents polarity on physicochemical properties and oil yield extracted from pumpkin (Cucurbita maxima) seed. Journal of Agricultural Biotechnology and Sustainable Development, 11(3), 40-47.

[19] Zahir, E., Saeed, R., Hameed, A. M., and Yousuf, A. (2014). Study of physicochemical properties of edible oil and evaluation of frying oil quality by Fourier Transform-Infrared (FT-IR) Spectroscopy. Arabian Journal of Chemistry, 1(1), 1-7.

[20] Lawton, C. L., Delargy, H. J., Brockman, J., Smith, F. C., Blundell, J. E. (2000). The degree of saturation of fatty acids influences post-ingestive satiety. The British Journal of Nutrition, 83(5), 473-482.

[21] Kostik, V., Memeti, S., and Bauer, B. (2010). Fatty acid composition of edible oils and fats. Journal of Hygienic Engineering and Design, UDC664.3:577.115.3

[22] FAO/WHO. (2009). Report of the $21^{\text {st }}$ session of the Codex Alimentarius Committee on fats and oils. Kola Kinabalu, Malaysia.

[23] Uhunmwangho, E. S. and Omoregie, E. S. (2017). Evaluation of nutritive, anti-nutritive and mineral content of Tetracarpidium conophorum (African walnut) seed oil at different stages of fruit maturation. Haya: Saudi Journal. Life Science, 2(6), 210-216.

[24] Sales-Campos, H., Souza, P. R., Peghini, B. C., da Silva, J. S., and Cardoso, C. R. (2013). An overview of the modulatory effects of oleic acid in health and disease. Mini Review in Medicinal Chemistry, 13(2), 201-210.

[25] Orsavova, J., Misurcova, L., Ambrosova, J. V., Vicha, R., and Mlcek, J. (2015). Fatty acids composition of vegetable oils and its contribution to dietary Energy intake and dependence of cardiovascular mortality on dietary intake of fatty acids. International Journal of Molecular Sciences, 16(6), 2871-2880. 